\title{
A Prospective Study of 50 Cases of Abdominal Wound Dehiscence - Etiology \& Its Management
}

\author{
Dr. J G Bhatt ${ }^{1}$, Dr. A D Desai ${ }^{2}$, Dr. J P Dave ${ }^{3}$ \\ ${ }^{1}$ M.S., Professor \& Head, Department of Surgery, P.D.U. Medical college and hospital, Rajkot, Gujarat, India \\ ${ }^{2}$ M.B.B.S, Resident Doctor, Department of Surgery, P.D.U. Medical college and hospital, Rajkot, Gujarat, India \\ ${ }^{3}$ M.S., Associate Professor, Department of Surgery, P.D.U. Medical college and hospital, Rajkot, Gujarat, India
}

\begin{abstract}
Background: In our study we identify the pre-operative and post operative risk factors causing wound dehiscence and also review its management. Objectives: To assess the various pre operative, post operative risk factors leading to wound dehiscence in patients undergoing emergency and elective abdominal operations and also study its management. Methodology: In this study 50 cases of postoperative abdominal wound dehiscence were studied at General Surgery Department, Civil Hospital Rajkot including all the patients >10 years who underwent abdominal operation and developed wound dehiscence. Results: Incidence rate was $4.9 \%$ with male to female ratio being 4:1 and most common age group being 31-40 years. Most common preoperative factors were anemia and cough while wound infection was most common post operative factor and dehiscence mainly occurred on $7^{\text {th }}$ day. Those treated with immediate suturing had early recovery while those treated conservatively or delayed suturing had prolonged hospitalization. Conclusion: Factors like older age group, male sex, anaemia, peritonitis and those who had undergone emergency operation, improper suture technique and improper aseptic precautions lead to wound dehiscence. Patients who developed wound dehiscences were managed either conservatively / immediate / delayed suturing of the wound or re-laparotomy was done.
\end{abstract}

Keywords: wound dehiscence, laprotomy, peritonitis, pallor, infection

\section{Introduction}

Abdominal wound dehiscence (WD) or burst abdomen is one of the most serious postoperative complication and is associated with high morbidity and mortality. It presents as a mechanical failure of wound healing of surgical incisions ${ }^{[1]}$. It occurs with an incidence of $0.4-3.5 \%$ after major abdominal surgeries with a related mortality of $10-45 \%$.

Despite advances in operative techniques and risk control methods during recent years, the incidence of WD remains high. WD is a devastating incident that can cause pain, mental distress, infectious complications and financial burdens for the patient, as well as complications including evisceration and reoperation.

Our institute is facing the problem of wound dehiscence frequently. This has lead us to study the frequency, risk factors, management \& complications of wound dehiscence.

\section{Materials And Methods}

A prospective study of was conducted in the Department of Surgery, P.D.U Government Medical College and Hospital, Rajkot, Gujarat, India. It was undertaken from October 2015 to September 2016. A total number of 50 Patients admitted in department of general surgery and underwent routine and emergency laparotomies who developed abdominal wound dehiscence where included in the study. Patients with previous laparotomies and Patients age below 18 years were excluded from the study.

A detailed study of these patients were done as per Proforma regarding following factors:- Underlying pathology, Emergency/Elective Laparotomy, Type of Incision, Age, Haemoglobin $(<10 \mathrm{~g} / \mathrm{dl})$, Hypoproteinaemia, Poor
Nutritional status $($ BMI<18.5) Obesity $\quad($ BMI>29.9), Diabetes Mellitus, Malignancy/Chemotherapy, Postoperative cough, Pulmonary Diseases with cough, Postoperative abdominal distension due to paralytic ileus, Postoperative vomiting, hiccough, or other straining factors. ${ }^{[2,3,4,5]}$

On the basis of above outcome and results, data was statistically analyzed to reach a definite conclusion regarding predictors leading to post-operative abdominal wound dehiscence.

\section{Inclusion Criteria}

Patient admitted in department of general surgery and undergoing routine and emergency laparotomies who develops abdominal wound dehiscence after Laparotomy.

\section{Exclusion Criteria}

Patients with previous laparotomies.

Patients with age below 18 yrs.

\section{Results}

A total of 50 patients who developed wound dehiscence was included in the study, Out of these 05 patients had developed complete disruption of abdominal wound (burst abdomen). $45(90 \%)$ cases had the dehiscence occurring in emergency procedures. Incidence was highest in cases of midline incision, as it was commonly used incision. In emergency laparotomy group, GI perforation were 30 cases suggesting intra-abdominal sepsis as a risk factor, poor nutritional status, anaemia, post-operative cough were found significant as the risk factors. Incidence of wound dehiscence is most common in age group of 31-40 years \& most common post operative day is $7^{\text {th }}$. 22 patients were managed conservatively in the form of application of abdominal

Volume 6 Issue 1, January 2017 


\section{International Journal of Science and Research (IJSR) \\ ISSN (Online): 2319-7064}

Index Copernicus Value (2015): 78.96 | Impact Factor (2015): 6.391

binder \& 10 patients were managed by delayed suturing after subsidence of infection.

Incidence of wound dehiscence in different age groups

\begin{tabular}{|c|c|c|}
\hline Age & No. of cases & Percentage \\
\hline $18-30$ & 9 & 18 \\
\hline $31-40$ & 12 & 24 \\
\hline $41-50$ & 8 & 16 \\
\hline $51-60$ & 11 & 22 \\
\hline $61-70$ & 9 & 18 \\
\hline$>70$ & 1 & 2 \\
\hline & 50 & 100 \\
\hline
\end{tabular}

Wound dehiscence in relation to type of incision

\begin{tabular}{|c|c|c|}
\hline Type of incision & No. of Cases & Percentage \\
\hline Upper Midline & 17 & 34 \\
\hline Mid Midline & 25 & 50 \\
\hline Lower Midline & 3 & 6 \\
\hline Kocher's & 2 & 4 \\
\hline Rt paramedian & 1 & 2 \\
\hline Mcburneys incision & 2 & 4 \\
\hline & 50 & 100 \\
\hline
\end{tabular}

Primary disease leading to burst abdomen

\begin{tabular}{|c|c|c|}
\hline Diagnosis & No of pts. & Percentage \\
\hline GI perforation & 30 & 60 \\
\hline Cholelithiais & 2 & 4 \\
\hline Appendicular pathology & 3 & 6 \\
\hline Intestinal obstruction & 12 & 24 \\
\hline Malignancy & 2 & 4 \\
\hline Obstructed inguinal hernia & 1 & 2 \\
\hline & 50 & 100 \\
\hline
\end{tabular}

Risk factors associated with wound dehiscence

\begin{tabular}{|c|c|c|}
\hline Risk Factors & No of patients & Percentage \\
\hline Anaemia & 32 & 64 \\
\hline Emergency surgery & 45 & 90 \\
\hline Post-operative cough & 20 & 40 \\
\hline Malnutririon & 25 & 50 \\
\hline Peritonitis & 30 & 60 \\
\hline
\end{tabular}

Time of disruption of abdominal wound

\begin{tabular}{|c|c|}
\hline Post op day & No of cases \\
\hline $5^{\text {th }}$ & 4 \\
\hline $6^{\text {th }}$ & 5 \\
\hline $7^{\text {th }}$ & 12 \\
\hline $8^{\text {th }}$ & 4 \\
\hline $9^{\text {th }}$ & 10 \\
\hline $10^{\text {th }}$ & 11 \\
\hline $11^{\text {th }}$ & 2 \\
\hline $12^{\text {th }}$ & 2 \\
\hline & 50 \\
\hline
\end{tabular}

Partial / Complete wound dehiscence

\begin{tabular}{|c|c|c|}
\hline Type of burst & No of patients & Percentage \\
\hline Complete & 05 & 10 \\
\hline Partial & 45 & 90 \\
\hline & 50 & 100 \\
\hline
\end{tabular}

\section{Management of Burst Abdomen}

\begin{tabular}{|c|c|}
\hline Treatment & No of patients \\
\hline Conservative & 22 \\
\hline Immediate suturing & 10 \\
\hline Delayed suturing & 18 \\
\hline & 50 \\
\hline
\end{tabular}

Total hospital stay

\begin{tabular}{|c|c|}
\hline Total days & No of patients \\
\hline $0-10$ & 8 \\
\hline $11-20$ & 12 \\
\hline $21-30$ & 26 \\
\hline$>30$ & 4 \\
\hline & 50 \\
\hline
\end{tabular}

\section{Discussion}

Wound dehiscence after abdominal operation is a multifactorial problem in which local and systemic factors are involved. Surgical expertise, type of incision, suturing material, surgical site infection, nutritional status, persistent cough, abdominal distension, leakage of pancreatic enzymes , anaemia, obesity, diabetes, jaundice, old age, emergency operation, colon surgeries, and late wound healing due to malignancy have all been suggested to predispose to wound dehiscence. Some of these factors are unavoidable.

Morbidity in the form of prolonged hospital stay, increased economic burden on health care resources and long term complication of incisional hernia can be reduced by highlighting the risk factors for wound dehiscence, the incidence rate and remedial measures to prevent or reduce the incidence of wound dehiscence.

This study has analysed the possible causes and risk factors of wound dehiscence, the management of these patients preoperatively, intra-operatively, postoperatively and evaluated the outcome of each case.

Our study showed maximum incidence of wound dehiscence in the age group of 31-40 years which is in line with other studies such as Wolff $^{6}$ and Maingot $^{7}$.

In Our clinical study, a total of 50 cases that developed wound dehiscence were included. Spectrum of cases from complete disruption of abdominal wound dehiscence, to wound gaping were included and 05 cases with complete disruption of abdominal wound (burst abdomen) were present in our study.

Study conducted on 107 patients with abdominal wound dehiscence over a period of 7 years in Department of Surgery, Case Western, Reserve University, Cleveland Veterans Affair's Medical Center USA, showed that patients with Intra-abdominal infection were more likely to have undergone an emergency operations, wound dehiscence is more common emergency operation and operations with higher wound classification. ${ }^{8}$ Our study showed that abdominal wound dehiscence is more commonly in patients operated for peritonitis due to gastro-intestinal perforation.

30 of the patients studied were operated for gastro-intestinal perforation. A total of 45 patients $(90 \%)$ who underwent emergency surgery developed abdominal wound dehiscence. 3 patients who developed dehiscence had appendicular pathology either perforation or acute appendicitis and 12 patients had small bowel obstruction and 2 patients had underlying malignancy. For the patients with bowel perforation which were classified mostly into contaminated 


\section{International Journal of Science and Research (IJSR) \\ ISSN (Online): 2319-7064}

Index Copernicus Value (2015): 78.96 | Impact Factor (2015): 6.391

surgical wounds, the procedure performed was peritoneal lavage with perforation closure. Patients with appendicular perforation underwent appendicectomy with peritoneal toilet. Most patients diagnosed with small bowel obstruction underwent resection and anastamosis and adhesiolysis.

Study conducted in Department of Surgical Gastroenterology, University of Copenhagen, Hvidovre Hospital in 2001, ${ }^{9}$ shows that the incidence of abdominal wound dehiscence and burst abdomen is more common in patients with vertical incision than in those with transverse incision. In our study out of 50 patients 45 patients underwent surgery with midline incisions had wound dehiscence, as mid-line incision was most commonly practiced in majority of cases. Two patients each with Kocher's and Mcburney's incision developed wound dehiscence and 1 patient developed wound dehiscence after right paramedian incision.

In a study carried out at Oula University Hospital, among 48 patients who developed wound dehiscence, there were 31 $(65 \%)$ patients with pre-operative hypoalbuminemia ${ }^{6}$, other risk factors included anemia ${ }^{7}$, malnutrition, chronic lung disease $^{10}$ and emergency procedure. In our study out of 50 patients about $32(64 \%)$ of patients had anaemia. Other risk factors in the study included Poor Nutritional status (BMI<18.5) 50\% and Post-operative cough $40 \%$.

According to bailey, the maximum incidence is found on $8^{\text {th }}$ post operative day. Study conducted at long island jewish medical centre showed the average post operative day of abdominal wound dehiscence to be 11.1 postoperatively. ${ }^{11}$ The explanation for the maximum incidence of burst abdomen on $7^{\text {th }}$ post operative day may be due to holding capacity of the sutures is reduced gradually \& attains peak around $7^{\text {th }}$ day, due to infection or sloughing of wound margins.

In our study, 22 out of 50 patients were treated conservatively. Those patients who were not lit for surgery were treated conservatively in form of daily dressings. Day by day healthy granulation tissue developed and the wound healed by secondary intention.

10 out of 50 patients were treated by immediate resuturing of the wound. Resuturing was done as mass closure with Ethilon no. 1. Eighteen patients out of 50 were treated initially with conservative treatment and then, when granulation tissue developed, delayed suturing was performed. Maingot in 1957 described that patients treated with conservative treatment had prolonged hospitalization and more morbidity as compared to patients treated by immediate resuturing.

Because of burst abdomen, the total duration of hospital stay increases and patients are discharged after prolonged hospitalization. Patients treated with conservative treatment or with delayed suturing had prolonged hospitalization. In a study carried out at Oula university Hospital,among 48 patients who developed wound dehiscence, the mean hospital stay was $25+/-15$ days. In our study 10 of the patients with partial disruption were closed by immediate resuturing or delayed resuturing which decreased the hospital stay to an average of 40 days as compared to conservative method where the average stay was 60 days. Mean Hospital stay in our study was 21-30 days.

\section{Conclusion}

Burst abdomen is a serious sequel of impaired wound healing. It occurs most commonly in the 31-40 year age group. predominately in males and vertical midline abdominal incisions. Many factors can pre-dispose to this grave complication. Knowledge of the more common mechanisms and how to avoid or overcome these hazards should help to reduce the incidence of this dangerous complication

Significant risk factors for the development of post operative abdominal wound dehiscence are:

1) Patient factors like older age group, male sex, anaemia, malnutrition, obesity, patients with peritonitis due to bowel perforation, intestinal obstruction, those who have undergone operation to emergency and those who have undergone perforation closure, resection and anastomosis.

2) Surgeon factors like midline incisions, improper suture technique and improper aseptic precautions which may lead to wound infection and then wound dehiscence.

3) Postoperative abdominal wound dehiscence can be prevented by improving the nutritional status of the patient, strict aseptic precautions, improving patients respiratory pathology to avoid postoperative cough.

4) Patients who developed burst abdomen were managed either conservatively or surgically. Surgically either immediate suturing of the wound or delayed suturing of the wound was done.

\section{References}

[1] Wagar SH, Malil: Zl, Razzaq A, Abdulah MT, Shaima A, Zahid MA. Frequency and risk factors for wound dehiscence/burst abdomen in midline laparotomies. J Ayub Med Coll Abbottabad 20050ct-Dec;7(4):

[2] Vinay k, Abbas AK, Fausto N: Robbins and Cotran Pathologic Basis of Diseases, ed 7. New Delhi, Elsevier, 2005, p $\underline{\text { 87-118. }}$.

[3] Carlson MA: Acute wound failure. Surg Clin North Am 1997;77: 607-6361 Evers

[4] Leong M, Phillips LG: Wound Healing. In Townsend CM, Bmuchamp RD. BM, Mattox KL (eds): SABISTON Textbook of Surgery, ed 17. New Delhi, 2005, p 183-208.

[5] Makela JT, Kjviniemi H, Juvonen T, Laitinen S. Factors influencing wound dehiscence after midline laparotomy. Am J Surg 1995; 172:387-90.

[6] Wolff W1. Disruption of abdominal wounds. Ann Surg 1950; 131: 534-55.

[7] Maingot's Abdominal Operations, International Edition, edited by Michael J. Zinner, Seymour J. Schwartz, Harold Ellis, 10th edition, pp. 416-422.

[8] Granam DJ, Stevenson JT, Mettenry CR. Association of intrabdominal infections and abdominal wound dehiscence. Am Surg 1998 Jul;64(7): $\underline{600-5}$.

\section{Volume 6 Issue 1, January 2017




\section{International Journal of Science and Research (IJSR) \\ ISSN (Online): 2319-7064}

Index Copernicus Value (2015): 78.96 | Impact Factor (2015): 6.391

[9] Grantcharov TP, Rosenberg J. Vertical compared with transverse incision in abdominal surgery. Eur J Surg 2001 Apr;167(4):260-7.

[10] Hampton JR. The burst abdomen. Br Med J. 1963 Oct 26;2(5364): 1032-103 5.

[11]Rjou JPA, Cohen JR, Johnson H. Factors influencing wound dehiscence. Am! Surg 1992 March;163:324-329.

Volume 6 Issue 1, January 2017

www.ijsr.net

Licensed Under Creative Commons Attribution CC BY 